\title{
TECHNOLOGICAL PROCESS SIMULATION FOR PRODUCING OF BIMETALLIC BILLET
}

\author{
Alexander SCHREK, Alena BRUSILOVÁ, Pavol SEJČ, Marcela POKUSOVÁ, Ondrej ŠAUŠA
}

Slovak University of Technology in Bratislava, Bratislava, Slovak Republic, EU, alexander.schrek@stuba.sk

https://doi.org/10.37904/metal.2019.813

\section{Abstract}

The assembling elements that were formed bimetallic billet in T-shape were chosen for lap joints creating of workpieces from thin sheets of metallic (Fe-Fe, Fe-Al) as well as metallic - nonmetallic (Fe-PMMA, Al-PMMA) materials by Resistance Element Welding method (REW). The tubes of $\mathrm{Cu} 99.9$ with dimensions $4 \mathrm{~mm} \times 0.5$ $\mathrm{mm}$ and a length of $11 \mathrm{~mm}$ filled with a brazing solder Sn60Pb40 were used for the elements producing. The required shape of elements is obtaining by the cold solid forming. Simulation by ANSYS software code was chosen for optimization of forming process and functional parts geometry of forming tool allowing to use only one extrusion forming operation. The simulations results are stresses, strains and modification of cross-section geometry of billets for three proposed forming modes. The functional parts geometry of tool was compared with the results of cross-section macroanalysis of billets made by laboratory tools. Also, REW joints of selected material combination that were subjected to macroanalysis were presented.

Keywords: Extrusion, strain, simulation, REW, forming tool

\section{INTRODUCTION}

Resistance Element Welding method (REW) is one of new assembly methods of the blanks from metallurgically unjoinable materials (Al-Fe, Plastic-Fe) [1-3]. This method is intended to create lap-joints. The principle is based on the heating of the assembling element between the connected blanks by resistance heating which leads to creating of solder joint. To create a joint It is possible to use standard technical accessories (welding nippers) intended for resistance spot welding (RSW) of the steel blanks. Correct joint geometry and the assembling element dimensions, as well as a chemical composition of the material for its creation, have significant influence to the required mechanical properties of the (REW) joint. During the joining steel to the aluminium, the assembling element end is brazed to the steel blank while the aluminium blank is bonded in a joint only through the mechanical wedging. The fusion welding joint is created between the assembling element and the blank along the whole circumference. The assembling element can be made of the aluminium alloy. The problem that occurs in this solution is in splashing of the melted material of the head of the assembling element which causes worse functional and aesthetic joint characteristics. Another solution is using of a bimetallic assembling element where the melting temperature of the cover material is higher than melting temperature of the core. A material combination of the cover from the $\mathrm{Cu} 99.9 \%$ tube with the diameter $\varnothing 4 \mathrm{~mm}$ and the wall thickness of $0.5 \mathrm{~mm}$ and the core from a Sn60Pb solder was suggested [4].For desired dimensions of the assembling element used to the REW applications is the blank created from tube filled with a solder is divided in the length of $11 \mathrm{~mm}$ as is shown on Figure 1.
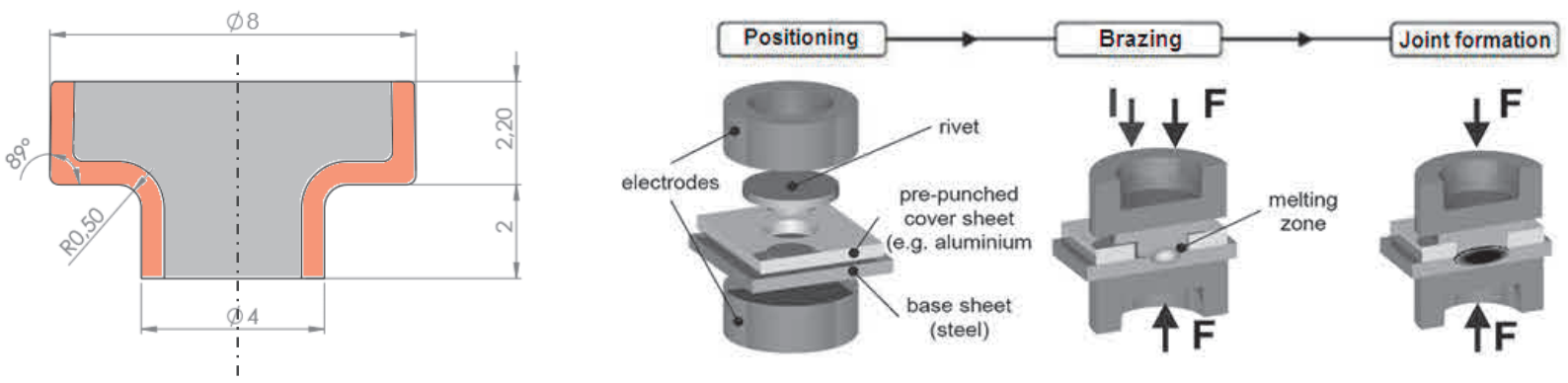

Figure 1 The assembling element and REW method [5] 
The cold forming process was chosen for the assembling element production. The head forming is possible to realize in several solutions. The goal was to find such a solution that allows us to achieve a desired shape in one forming operation, without formation of the internal defects [6]. The shape of the head was chosen in three variations as a flat shape (Figure $\mathbf{2 a}$ ), a concave shape at an angle of +10 degree (Figure $\mathbf{2 b}$ ) and a convex shape at an angle of -10 degree (Figure $2 \mathbf{c}$ ).

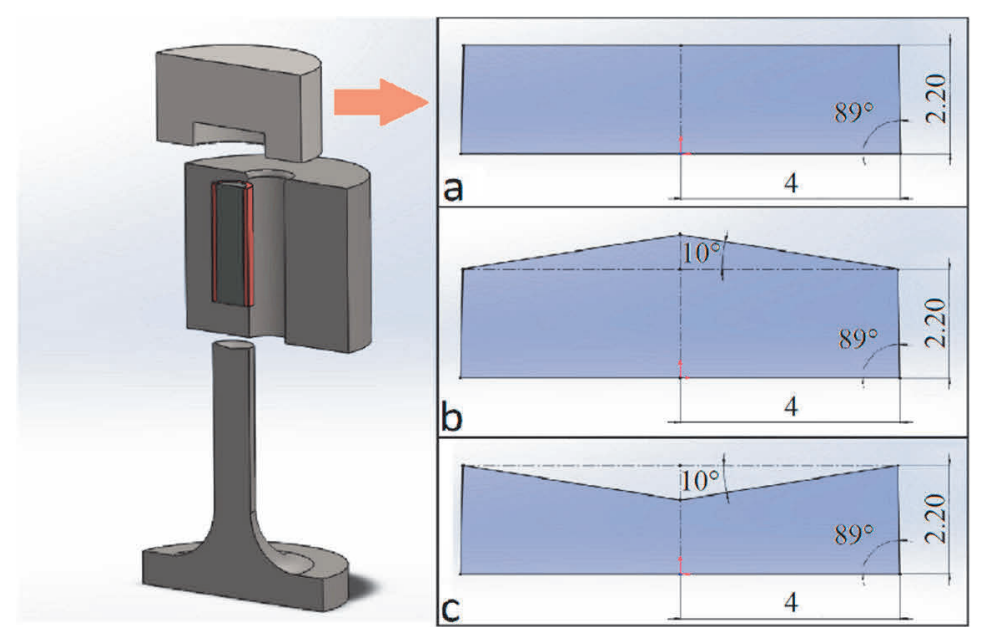

Figure 2 The head elements shapes

Figure 3 shows REW joint with significant defects of assembling element in significant strips form. The pores appeared in a solder but this is a metallurgical problem that wasn't a subject of this paper. As a solution of the problem of strips creation, the different geometry of punch which provide better material flow regulation as well as a mutual motion of a billet and a tool during the head formation, were suggested. The original process used upsetting where the proposed and confirmed process was based on a motion of billet against a punch creating the head element. The software ANSYS and practical experiments were used for a verification of the proposed alterations [7].

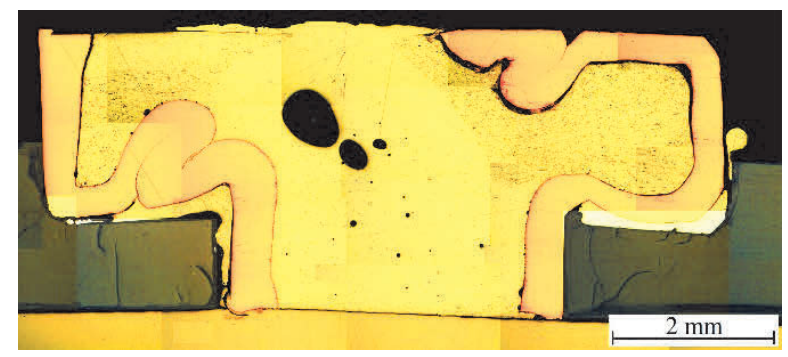

Figure 3 REW joint of combination a plastic - a galvanized steel sheet with defects in strips form

\section{MATERIALS PROPERTIES OF ASSEMBLING ELEMENT}

The stress-strain characteristics of both materials of bimetallic billet were used as the boundary conditions for simulation of element head formation except the model of tool geometry. They were determined using the tensile testing machine INSTRON 1195 (Table 1).

Table 1 Stress-strain characteristics of assembling element materials

\begin{tabular}{|c|c|c|c|c|c|c|c|c|}
\hline Material & $\begin{array}{c}\text { Density } \\
\left(\mathbf{g . c m}^{-3}\right)\end{array}$ & $\begin{array}{c}\text { Yield strength } \mathbf{R e} \\
(\mathbf{M P a})\end{array}$ & $\begin{array}{c}\text { Tensile } \\
\text { strength } \mathbf{R m} \\
(\mathbf{M P a})\end{array}$ & $\begin{array}{c}\text { Elongation } \\
\boldsymbol{A}_{R e} \\
(\%)\end{array}$ & $\begin{array}{c}\text { Elongation } \\
\boldsymbol{A}_{R m} \\
(\%)\end{array}$ & $\begin{array}{c}\text { Young } \\
\text { Modulus } \\
(\mathbf{G P a})\end{array}$ & $\begin{array}{c}\text { Poisson } \\
\text { ratio } \\
(-)\end{array}$ & $\begin{array}{c}\text { Tangent } \\
\text { Modulus } \\
(\mathbf{M P a})\end{array}$ \\
\hline $\mathrm{Cu}$ & 8.96 & 293 & 347.5 & 0.2 & 3.6 & 146 & 0.35 & $1,602.94$ \\
\hline SnPb40 & 8.5 & 40.2 & 61.5 & 1.3 & 10.8 & 30.1 & 0.38 & 224.32 \\
\hline
\end{tabular}




\section{TECHNOLOGICAL PROCESS SIMULATION}

For stresses and strains simulation of bimetal and overall strains and shape of billet, software ANSYS 18.2 was used. The billet motion velocity $v=2.67 \mathrm{~mm} \cdot \mathrm{s}^{-1}$, friction coefficient $f=0.1$, the element dimension in meshing function /meshing size $=0.25 \mathrm{~mm}$, temperature $T=20^{\circ} \mathrm{C}$, the definition of bimetal border line through the use of rough function, together with the tool geometry and stress-strain characteristics of materials, were used as the boundary conditions. The model of a simulation is illustrated in Figure 4. The head forming is performed by motion of a bottom punch together with billet up to the head die.
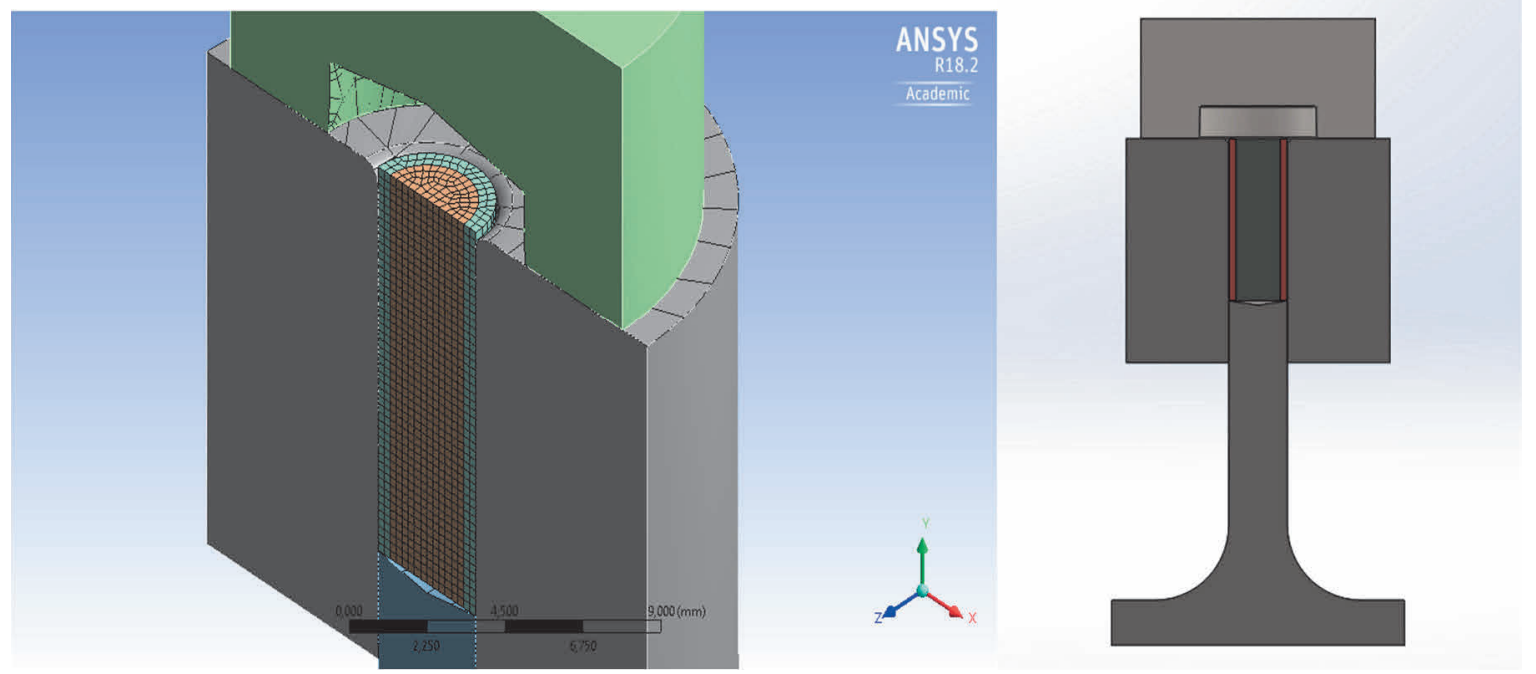

Figure 4 The model of tool system with billet for simulation

The values and distribution of stresses during the forming of the head element is illustrated in Figure $\mathbf{5}$. According to the simulation, it is necessary to obtain stresses down to $2250 \mathrm{MPa}$ for complete filling of die cavity and the bottom corners of head. There were found no indication of strips formation in simulations. The forces development depending on a stroke and time for single shapes alternatives is documented in Figure 6.

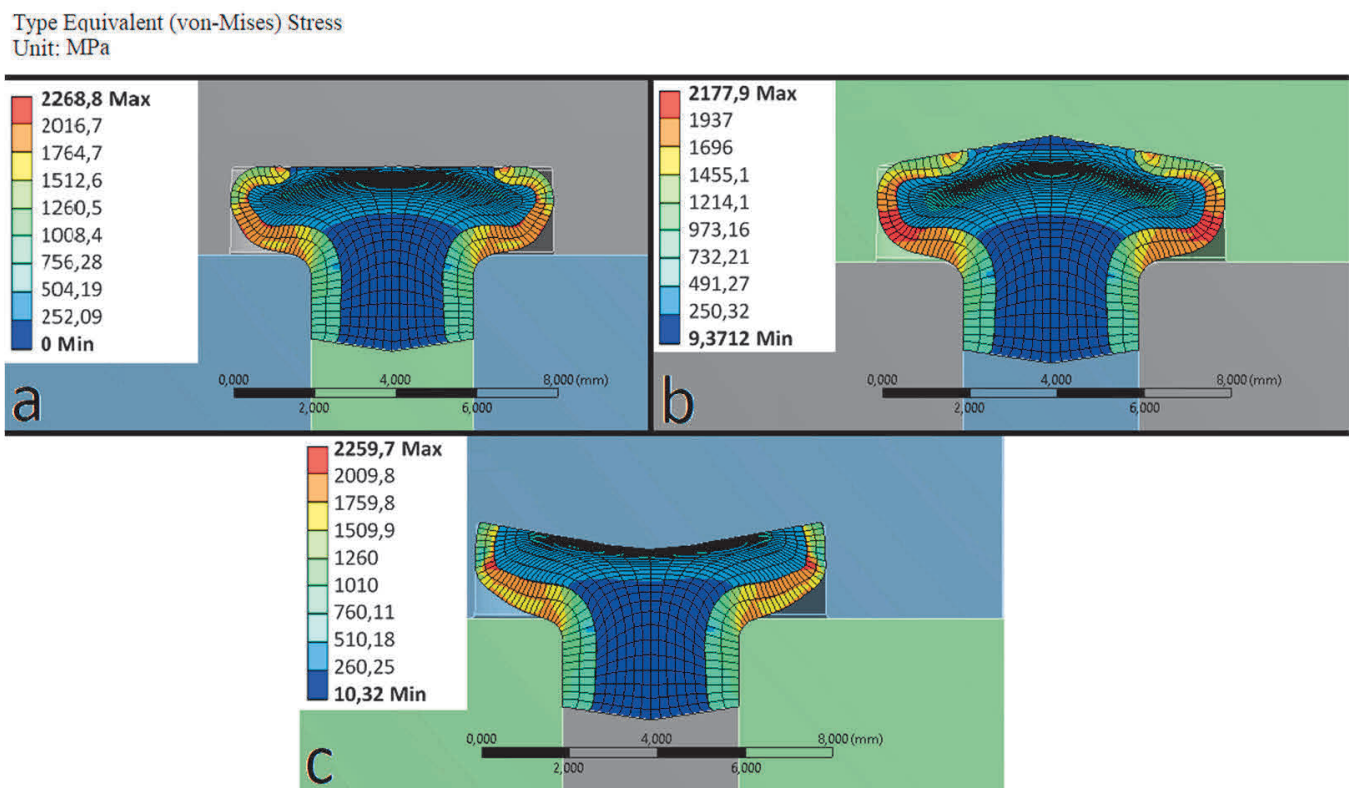

Figure 5 The distribution and values of stresses in a billet cross-section for single shapes alternatives 


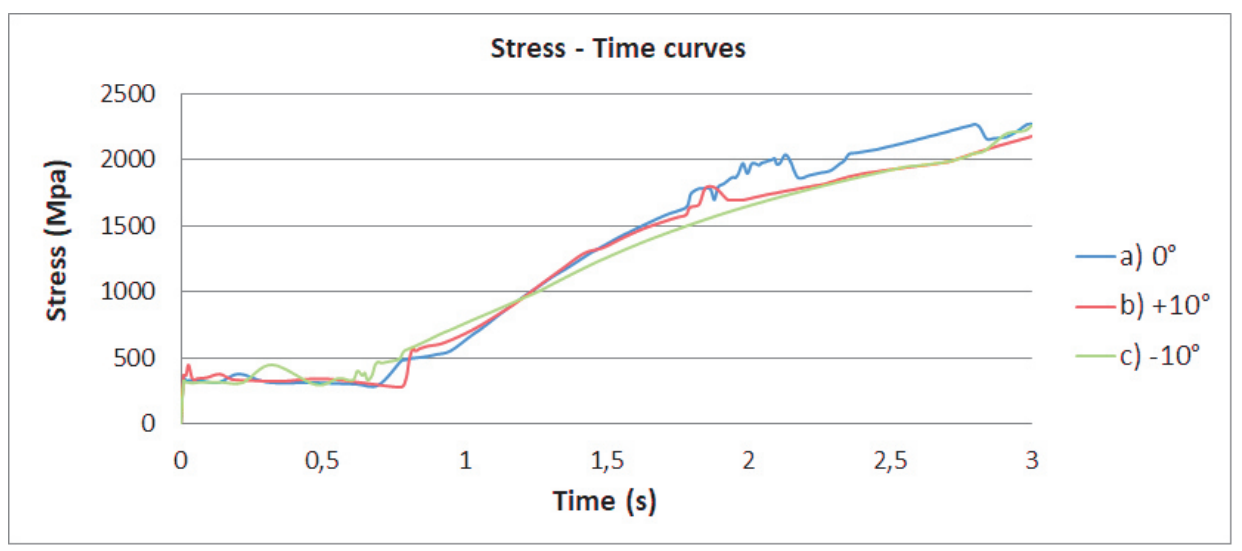

Figure 6 The stresses development during forming process for single alternatives

The strains dimensions and distribution in bimetal element during the head formation is shown in Figure 7. The largest strain values were obtained at the point of the biggest change of a cross-section. The strain of $\mathrm{Cu}$ tube cover (a wall thickness reducing and increasing) corresponds to changes of the diameter cross-sections.

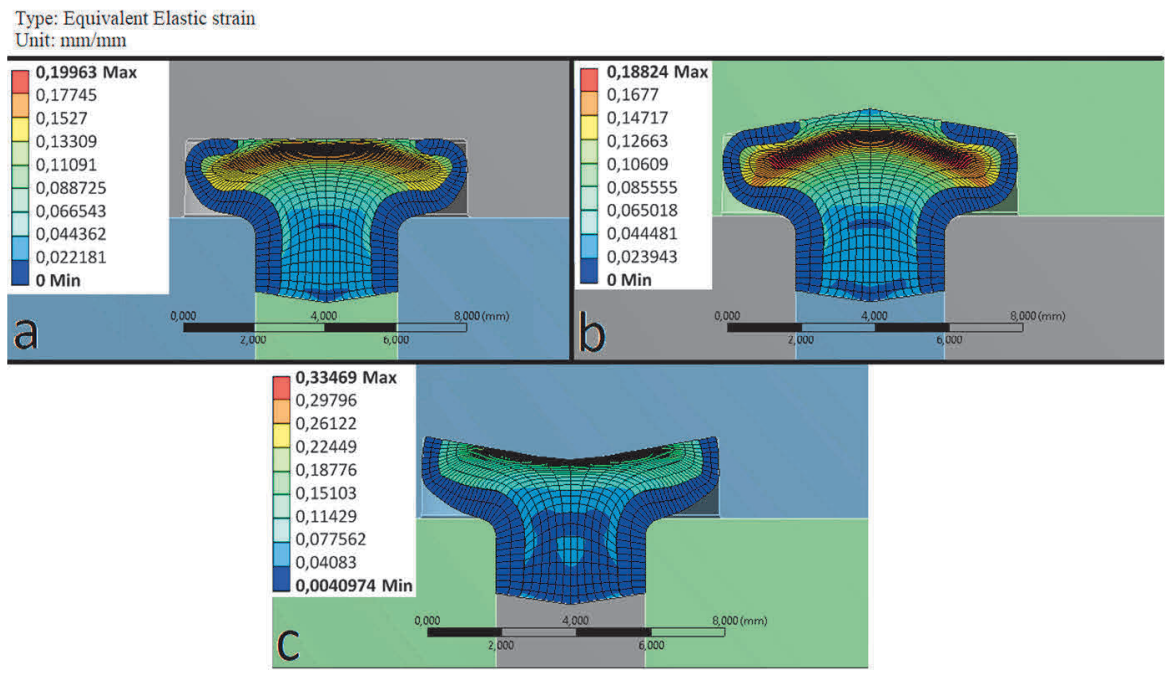

Figure 7 The strains development in bimetal during forming process for single shapes alternatives

Type Equivalent (von-Mises) Stress

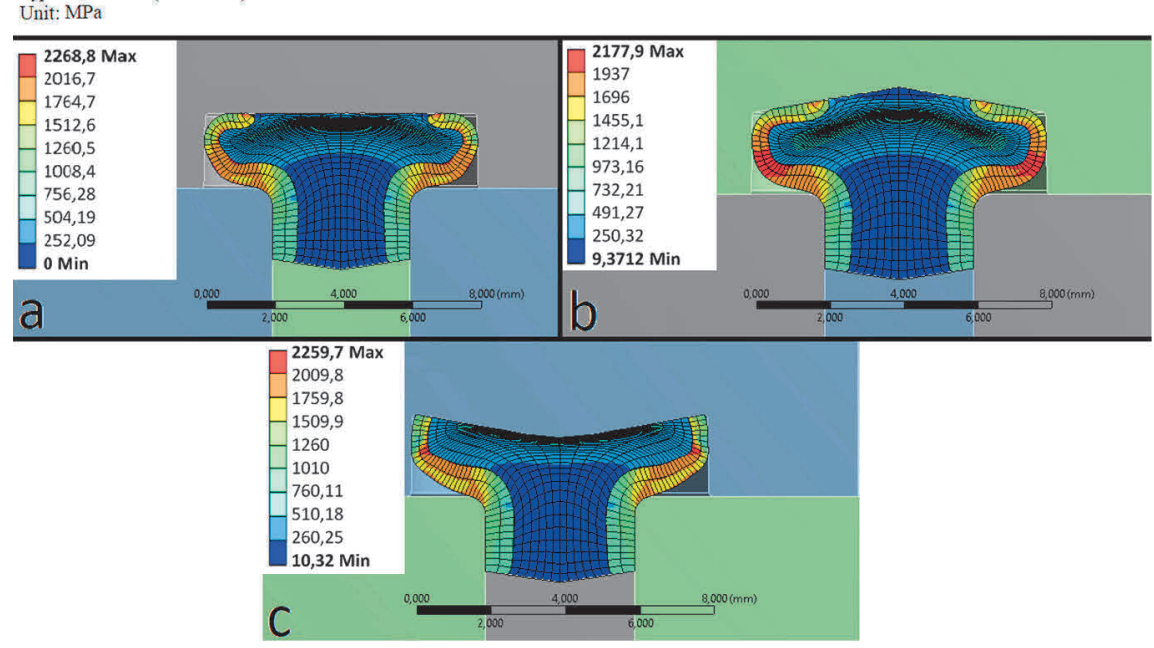

Figure 8 The overall strains development during forming process for single shapes alternatives 
The overall strains dimensions and distribution in element during the head formation is shown in Figure 8. The biggest strain was at the point of the biggest changes of the diameter cross-sectionions. There was zero strain in shank.

\section{EXPERIMENTS}

The assembling elements were formed on the tool with replaceable head forming punches on the hydraulic press DP1600 at the maximal forming force of $25 \mathrm{kN}$. The billets cross-sections were subject to macroscopic analysis with focusing to a cover strain, strips formation and overall symmetry (Figure 9).

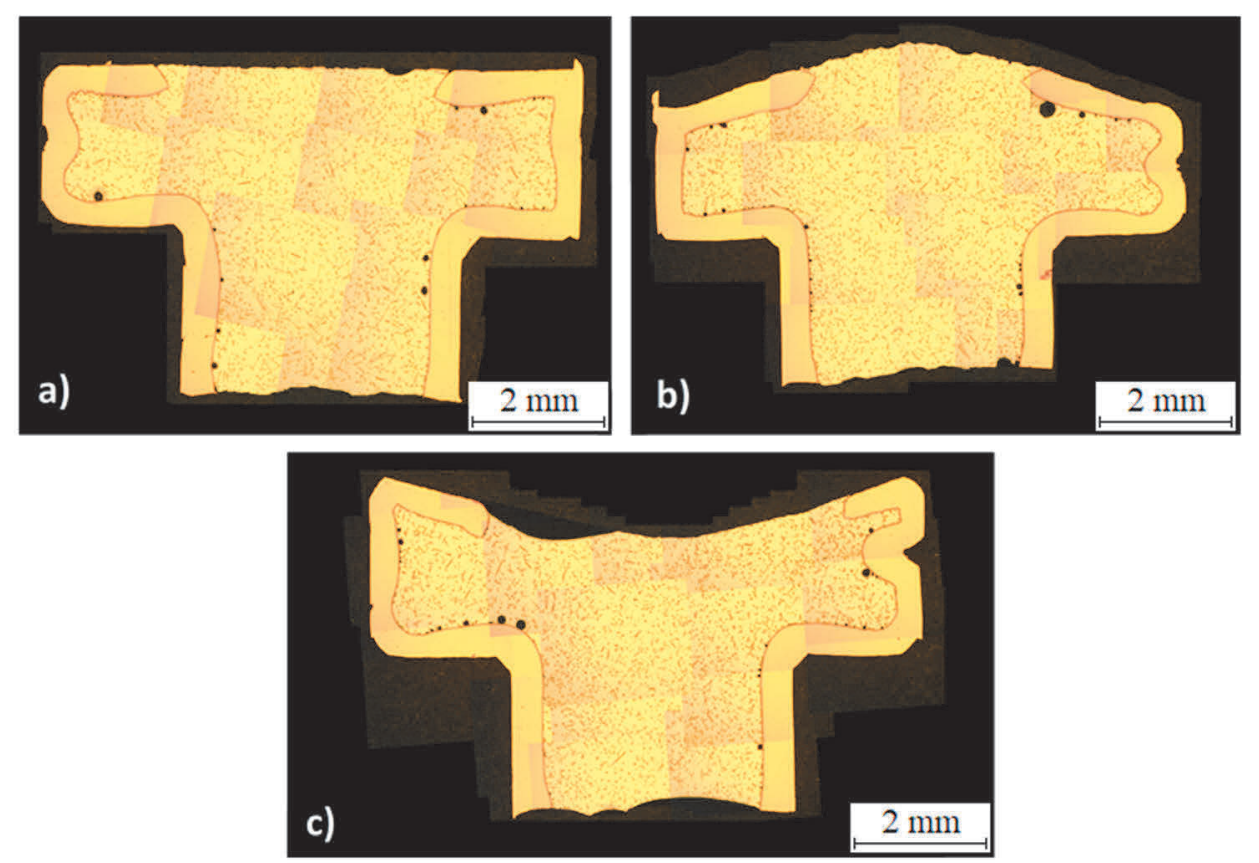

Figure 9 The macrostructure of billets cross-section

The workpieces in Figures $9 a$ and $9 b$ shows satisfactory symmetry with only a small indication of the strip formation. The workpiece in Figure $9 \mathrm{c}$ shows higher asymmetry that was caused by the formation of the bigger strip, however this shape is acceptable too in comparison to the initial upsetting head forming experiments. The interesting microstructure appears, microstructure does not have a texture after forming but have a dendritic structure. This dendritic structure was created during the pressing of samples into a plastic at the temperature of $190^{\circ} \mathrm{C}$. The brazing structure demonstrated a pre-crystallization process.

\section{CONCLUSION}

Resistance Element Welding (REW) is appropriate method for non-metallurgical lap-joints creating of the material blanks in combination Al-Fe or Plastic-Fe. The joint is created through the assembling element but by brazing (not by the welding) what have an effect on a heat influence decreasing of the joint. The experiments showed that the assembling element had to be solved in bimetallic form. This solution eliminated the splash problem of the assembling element material which decreased functional and aesthetic joint characteristics. The goal of the assembling elements production was to create a product with a minimum of internal defects like asymmetry of solder and $\mathrm{Cu}$ tube cover, as well as significant strips of $\mathrm{Cu}$ tube cover which negatively affecting the brazing process. The assembling elements were made of billet that was formed from a thin-walled $\mathrm{Cu}$ tube filled Sn60Pb solder. From many types of solid cold forming processes for the head shaping, the single-function technological process was chosen and confirmed by the simulation. This procedure eliminates 
the buckling stiffness problem of the "free" billet part causing undesired strips formation. The stress-strain characteristics of materials bimetal determined by mechanical testing were used for the ANSYS 18.2 simulation software. The tool model with different geometries of the head forming part was part of the simulation process. The simulation and the experiments results confirmed the accuracy of the proposed technological process. This procedure will be used for the productive progressive tool, which will be used for cutting of bimetal on a dimension and the assembling element forming. The proposed and verified method of bimetallic billets production will be also used for other products dimensions.

\section{ACKNOWLEDGEMENTS}

This work was supported by the Slovak Research and Development Agency under the contract No. PVV-16-0485 and University Science Park STU Bratislava "ITMS code 26240220084. We would like to thank the Slovak grant agency VEGA for the financial support of the project VEGA 1/0405/19.

\section{REFERENCES}

[1] KAZANOWSKI, P., EPLER, M.E. and MISIOLEK, W.Z. Bi-metal rod extrusion - process and product optimization. Materials Science and Engineering: A. 2004. vol. 369, no. 1-2, pp.170-180.

[2] HAGHIGHAT, H. and MAHDAVI, M.M. Analysis and FEM simulation of extrusion process of bimetal tubes through rotating conical dies. Trans. Nonferrous Met. Soc. China. 2013. vol. 23, no. 11, pp. 3392-3399.

[3] MESCHUT, G., SCHMAL, Ch. and OLFERMANN, T. Process characteristics and load-bearing capacities of joints welded with elements for the application in multi-material design. Welding in the World. 2017. vol. 61, no. 3, pp. 435-442.

[4] KHOSRAVIFARD, A. and EBRAHIMI, R. Investigation of parameters affecting interface strength in Al/Cu clad bimetal rod extrusion process. Materials \& Design. 2010. vol. 31, no. 1, pp. 493-499.

[5] MESCHUT, G., HAHN, O., JANZEN, V. and OLFERMANN, T. Innovative joining technologies for multi-material structures. Welding in the World. 2014. vol. 58, no. 1, pp. 65-75.

[6] QAMAN, S.Z., PERVEZ, T. and CHEKOTU, J.Ch. Die Defects and Die Corrections in Metal Extrusion. Metals. 2018. vol. 8, no. 6 , art. No. 380.

[7] ZHENG, P.F., CHAN, L.C. and LEE. T.C. Numerical analysis of the sheet metal extrusion process. Finite Elements in Analysis and Design. 2005. vol. 42, no. 3, pp. 189-207. 